\title{
How Water Advances on Superhydrophobic Surfaces
}

\author{
Frank Schellenberger, Noemí Encinas, Doris Vollmer, and Hans-Jürgen Butt \\ Max Planck Institute for Polymer Research, Ackermannweg 10, 55128 Mainz, Germany
}

(Received 15 December 2015; published 29 February 2016)

\begin{abstract}
Superliquid repellency can be achieved by nano- and microstructuring surfaces in such a way that protrusions entrap air underneath the liquid. It is still not known how the three-phase contact line advances on such structured surfaces. In contrast to a smooth surface, where the contact line can advance continuously, on a superliquid-repellent surface, the contact line has to overcome an air gap between protrusions. Here, we apply laser scanning confocal microscopy to get the first microscopic videos of water drops advancing on a superhydrophobic array of micropillars. In contrast to common belief, the liquid surface gradually bends down until it touches the top face of the next micropillars. The apparent advancing contact angle is $180^{\circ}$. On the receding side, pinning to the top faces of the micropillars determines the apparent receding contact angle. Based on these observations, we propose that the apparent receding contact angle should be used for characterizing superliquid-repellent surfaces rather than the apparent advancing contact angle and hysteresis.
\end{abstract}

DOI: 10.1103/PhysRevLett.116.096101

Research on the wetting of micro- and nanostructured surfaces is motivated by the challenge to control wetting, in particular, to fabricate surfaces which repel liquids. Superliquid-repellent surfaces are, for example, selfcleaning [1], can reduce hydrodynamic drag [2], and are used for fog harvesting [3,4], enhancing heat transfer [5], and gas exchange [6]. One strategy to achieve superliquid repellency is to structure low-energy surfaces on the nanoand micrometer length scale. This structure needs to be such that protrusions keep the drop from direct contact with the substrate. A layer of air is maintained underneath the drop leading to the so-called Cassie or Fakir state [7-13]. In contrast, when the liquid wets the surface without trapping air, in the so-called Wenzel state, superliquid repellency is lost.

For an understanding of the wetting behavior of drops on superliquid-repellent surfaces, most progress has been made using superhydrophobic micropillar arrays [8,14-16]. One of the open questions is how does a drop advance on a superhydrophobic surface? First insight into the microscopic process was obtained by recent theoretical studies using surface evolver [17] or energy minimizations [18]. For modeling advancing drops, these methods are, however, restricted to the Wenzel state. From the experimental side, in by far most publications on superhydrophobic surfaces, apparent receding contact angles above $150^{\circ}$ and advancing contact angles below $170^{\circ}$ were reported (Table S1 in the Supplemental Material [19] and [1,7,8,14,20-94]). Hardly without any exception, apparent contact angles are measured using a goniometer in combination with a video camera and drop shape analysis. However, measuring contact angles above $150^{\circ}$ is difficult. For high contact angles, the narrow gap between the liquid and the solid makes it hard to identify the position of the contact line
[95-97], and drop vibrations can change the result [98]. Gao and McCarthy [96], Bartell and Shepard [99], and Extrand [100] speculated that the advancing contact angle could take $180^{\circ}$. To our knowledge, no simulation or measurement exist that confirm or falsify this hypothesis.

Progress in our understanding of the intimate relationship between nano- and microstructure and macroscopic wetting phenomena has been hampered by the lack of microscopic images of advancing drops. Using scanning electron microscopy $[20,101,102]$ and confocal microscopy [103], the contact lines of static drops have been imaged with a resolution better than $1 \mu \mathrm{m}$. However, the process of a moving contact line and, in particular, the limiting case, the contact angle just before advancing has never been imaged.

Here, we used an inverted laser scanning confocal microscope to image the advancing and receding side of water drops sliding on superhydrophobic micropillar arrays. To let drops move, we carefully tilted the vibration isolation table onto which the microscope was mounted by hand with a hydraulic car jack. The inclination angle was measured with an optical beam. After recording confocal microscope videos, they were further processed (Supplemental Material [19], Fig. S1). Superhydrophobic arrays of cylindrical micropillars (Fig. 1 and Supplemental Material [19]) with flat top faces were fabricated as described in Ref. [103]. Three different square arrays of epoxy-based SU-8 with pillar diameters $a$ and pillar spacings $b$ of 5 and $15 \mu \mathrm{m}, 10$ and $30 \mu \mathrm{m}$, and 25 and $75 \mu \mathrm{m}$, respectively, were investigated. The area fraction $f=\pi a^{2} / 4(a+b)^{2}=0.049$ was kept constant. The pillars were $9-16 \mu \mathrm{m}$ high. Apparent advancing and receding contact angles were measured with a goniometer (DataPhysics OCA 35) using the sessile drop method 

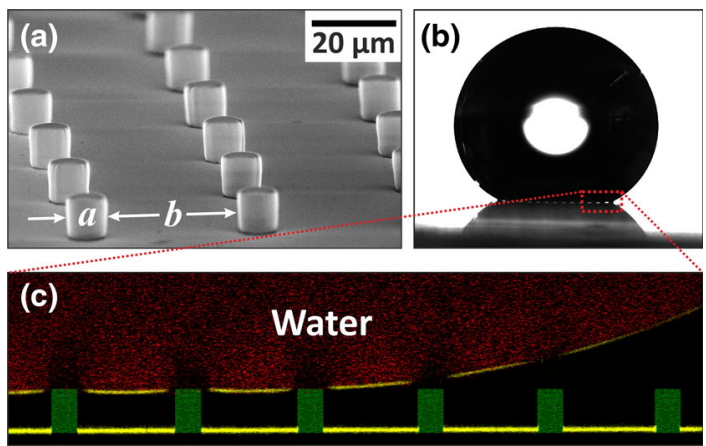

FIG. 1. (a) Scanning electron micrograph of an array of the cylindrical micropillars. Diameter and micropillar distance are indicated by $a$ and $b$, respectively. The microstructure consists of SU-8 coated with a $70 \mathrm{~nm}$ thick layer of silica and hydrophobized with $(1 \mathrm{H}, 1 \mathrm{H}, 2 \mathrm{H}, 2 \mathrm{H})$-perfluorooctyl-trichlorosilane via chemical vapor deposition. (b) Contour of a $2 \mathrm{~mm}$ high water drop on a micropillar array. (c) Confocal microscope vertical image of a water drop on a superhydrophobic micropillar surface ( $a=10 \mu \mathrm{m}, b=30 \mu \mathrm{m}$, pillar height $h=15 \mu \mathrm{m})$. We used an inverted confocal microscope (Leica TCS SP8 SMD, HCX PL APO $40 \times$ dry objective) with a resolution of about 0.25 and $1.0 \mu \mathrm{m}$ in the horizontal and vertical direction, respectively. Millipore water was fluorescently dyed with Alexa Fluor 488 at a concentration of $1 \mu \mathrm{g} / \mathrm{mL}$. The fluorescence of Alexa in water is shown in red. The surface tension as measured with the pendant drop method was $72.8 \pm 0.2 \mathrm{mN} / \mathrm{m}$; within this error, it did not change when adding Alexa. Reflection and emission signals were recorded simultaneously. Care was taken to ensure that the vertical sections of the imaging plane passed through the center of the drop. Confocal microscope videos were further processed (Supplemental Material [19], Fig. S1). The water-air (top yellow line) and substrate-air interfaces (bottom horizontal yellow line) are imaged in reflection. The interruptions in the yellow water-air interface are due to optical artifacts, as explained in Fig. S1 of the Supplemental Material [19]. The pillars (green) are simulated.

(3-5 $\mu \mathrm{L}$ water drops) to be $\Theta_{a}^{\mathrm{app}}=165 \pm 3^{\circ}$ and $\Theta_{r}^{\mathrm{app}}=$ $142 \pm 5^{\circ}$, respectively. The contact angles of water on an equally treated flat SU-8 surface after coating with a silica layer and hydrophobization were $\Theta_{a}=124^{\circ} \pm 2^{\circ}$ (advancing) and $\Theta_{r}=85^{\circ} \pm 5^{\circ}$ (receding). The errors were derived from repeated measurements with different samples. Within experimental resolution, we did not observe different apparent contact angles on the different geometries.

In the literature a number of definitions for contact angles are discussed $[18,104,105]$. We use the term "apparent" following e.g. Winkels et al. for the contact angle obtained by extrapolating the macroscopic fit of the contour to the horizontal going through the top faces of the micropillars [105]. With respect to "advancing" we follow e.g. Semprebon et al. [18], who used the term for the maximal, static contact angle on the advancing front.

An experiment starts by carefully placing a water drop of $5 \pm 1 \mu \mathrm{L}$ volume on the superhydrophobic surface. Then we gradually tilt the surface in the direction of one of the (a)
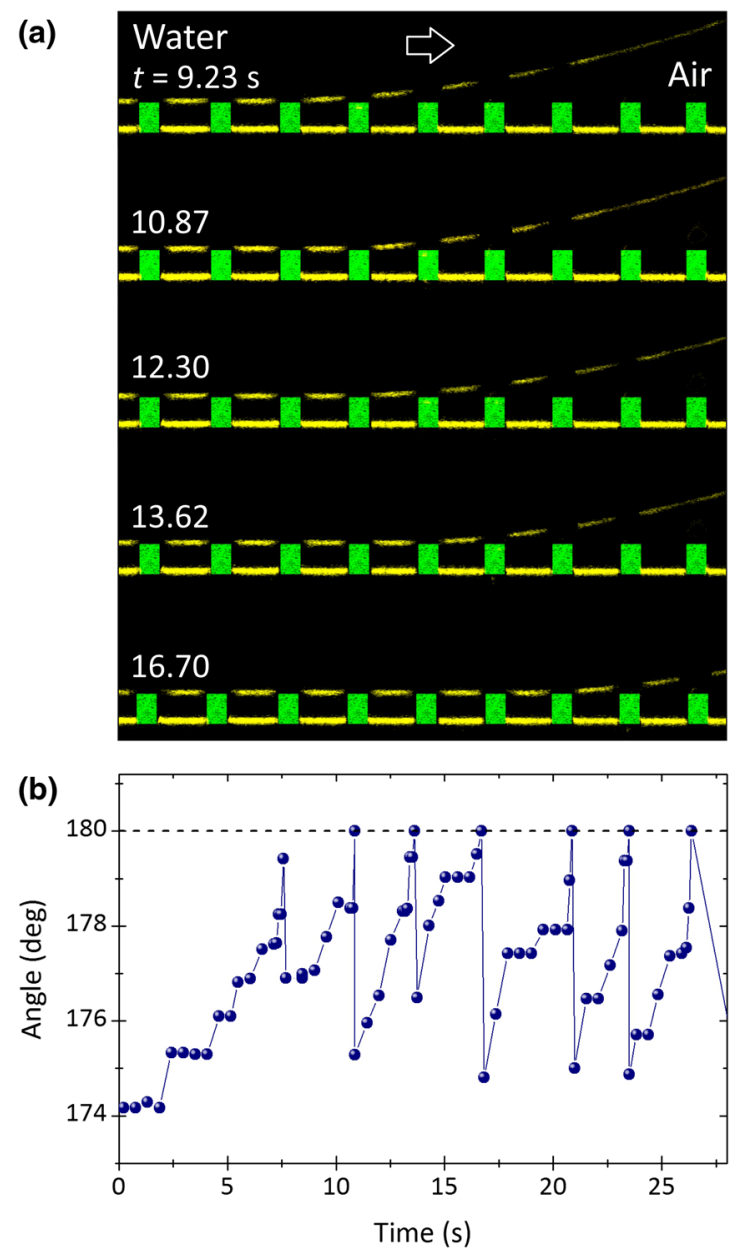

FIG. 2. Advancing waterfront on a superhydrophobic micropillar array. (a) Confocal vertical images of the advancing front of a water drop on a superhydrophobic micropillar surface ( $a=5 \mu \mathrm{m}, b=15 \mu \mathrm{m}, h=9 \mu \mathrm{m}$ ) before the drop starts rolling. The inclination of $9^{\circ}$ was kept constant. The water-air (top yellow line) and substrate-air interfaces (bottom horizontal yellow line) are imaged in reflection. (b) Advancing contact angles measured from confocal images plotted versus time. How contact angles were determined is shown in Fig. S2 of the Supplemental Material [19].

axes of the array. The drop distorts. At some inclination, the contact line starts to shift, and the apparent contact area becomes more elliptical. When the inclination reaches the roll-off angle of $\alpha=9^{\circ} \pm 1^{\circ}$, we observe an induction period. After typically $30 \mathrm{~s}$, the drop will start rolling off the surface.

When imaging the advancing front in the induction period with the confocal microscope, we observe that the contact line does not jump from one pillar to the next. Rather, sections of the liquid-vapor interface descend onto the top face of the next micropillar (Fig. 2 (main text) and the Supplemental Material, Video 1 [19]). In one representative sequence of images, the temporary contact angle increased from $174^{\circ}$ until it reached almost $180^{\circ}$ (Fig. 2). The top face 
of the next pillar was wetted after $7.6 \mathrm{~s}$ [Fig. 2(b)]. Contact with the next micropillars was established after 10.9, 13.6, $16.7,20.9,23.5$, and $26.4 \mathrm{~s}$. We call $\Theta_{a}^{\mathrm{app}}=180^{\circ}$ the apparent advancing contact angle. Thus, our observations verify the scenario proposed by Gao and McCarthy [96], Bartell and Shepard [99], and Extrand [100]. After 27 s the drop started its fast descent downhill. From the passing of the

(a)
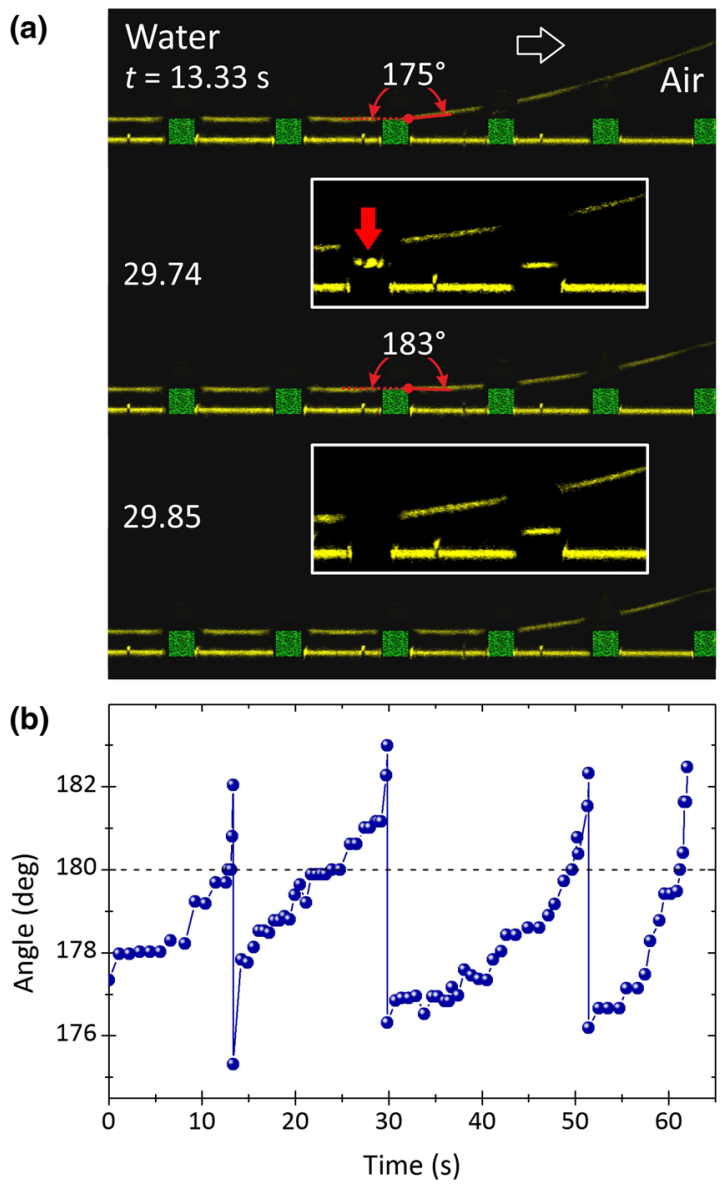

(c)
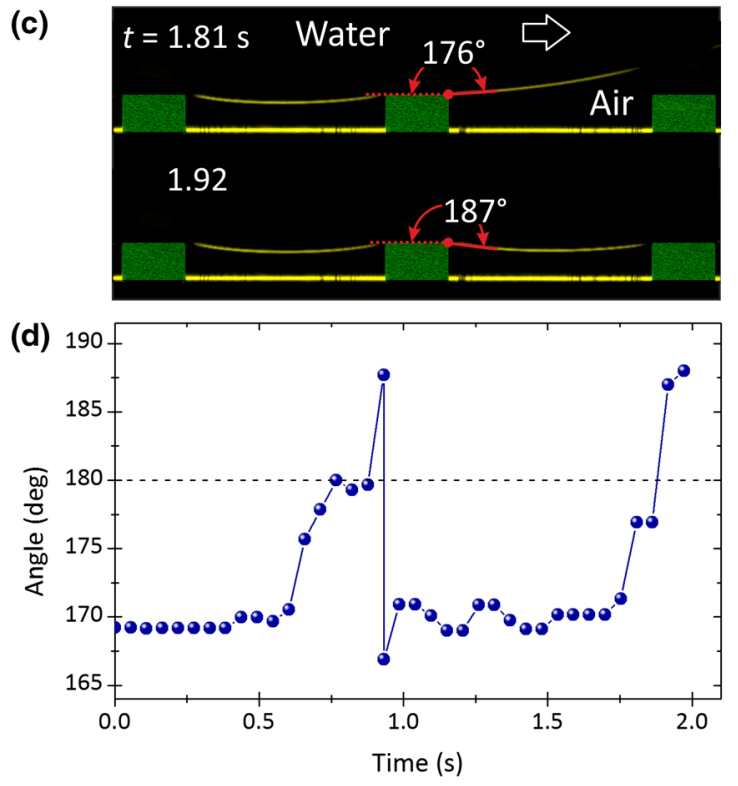

rear of the drop through the field of view a rolling velocity of the order of $1 \mathrm{~mm} / \mathrm{s}$ could be estimated.

Figure 2 was recorded on an array with a micropillar spacing of $b=15 \mu \mathrm{m}$. When using arrays with a larger dimension $(a=10 \mu \mathrm{m}, b=30 \mu \mathrm{m})$ the water surface even formed angles up to $183^{\circ}$ with the horizontal (Fig. 3 (main text) and Video 2 in the Supplemental Material). On arrays with the largest dimensions ( $a=25 \mu \mathrm{m}, b=75 \mu \mathrm{m})$, the advancing contact angle approached $188^{\circ}$ (Fig. 3 (main text) and Video 3 in the Supplemental Material). Angles above $180^{\circ}$ are possible because the liquid surface has a concave curvature. This curvature determined by the drop size via the Laplace equation is also observed between all pillars in the contact region [e.g., Fig. 3(c)]. When extrapolating the macroscopic contour of the drop, an advancing angle above $180^{\circ}$ leads to an apparent advancing contact angle of $\approx 180^{\circ}$.

In contrast to the advancing side, on the rear side of the drops (Fig. 4 (main text) and Video 4 in the Supplemental Material) we observed a discontinuous movement. The contact line is pinned until a certain lower critical contact angle $\Theta_{r}^{\text {app }}$ is reached. Then the liquid front jumps to the next pillar. Since $\Theta_{r}^{\text {app }}$ is the maximal stable apparent contact angle on the rear side of the drop, this angle is the apparent receding contact angle. For practical reasons, we measured the apparent contact angle at a height of $10 \mu \mathrm{m}$ above the pillars' top faces and not directly at the height of the top faces [indicated in Fig. 4 at $t=31.76 \mathrm{~s}$ ]. Reason: The curvature of liquid bridges directly at the top faces of the micropillars was relatively high. At a height of $10 \mu \mathrm{m}$, the error in determining the slope of the drop shape was lower. In this way, we obtain again the apparent contact angle because the same one would be obtained from a

FIG. 3. Waterfront advancing on a superhydrophobic micropillar array. (a) Confocal vertical images of a water drop just before advancing on a superhydrophobic micropillar surface $(a=10 \mu \mathrm{m}$, $b=30 \mu \mathrm{m}, h=10 \mu \mathrm{m})$. The inclination at the roll-off angle of $9^{\circ}$ was kept constant. The water-air (top yellow line) and substrate-air interfaces (bottom horizontal yellow line) are imaged in reflection. Insets show unfiltered details containing the fourth and fifth micropillar from the left. At $t=13.33 \mathrm{~s}$, the waterfront has just touched on the third pillar from the left. The water surface then gradually bends downwards, exceeds an angle of $180^{\circ}$ at $t=24 \mathrm{~s}$, and reaches an angle of $183^{\circ}$ at $t=29.74 \mathrm{~s}$. Afterwards, it touches the top face of the next pillar. Thus, at $t=29.85 \mathrm{~s}$, the angle needs to be counted from the fourth pillar from the left. The moment when the waterfront touches the top face of the next pillar can be clearly defined because the reflection due to the air gap observed in the unfiltered images disappears (insets, red arrow). (b) Angles measured from confocal images plotted versus time. The results were obtained from Video 2 in the Supplemental Material. (c) A water drop just before advancing on a superhydrophobic micropillar surface with $a=25 \mu \mathrm{m}, b=75 \mu \mathrm{m}$, and $h=14 \mu \mathrm{m}$. The inclination at the roll-off angle of $8.5^{\circ}$ was kept constant. (d) Angles measured from confocal images plotted versus time. The results were obtained from Video 3 in the Supplemental Material. 


\section{(a)}

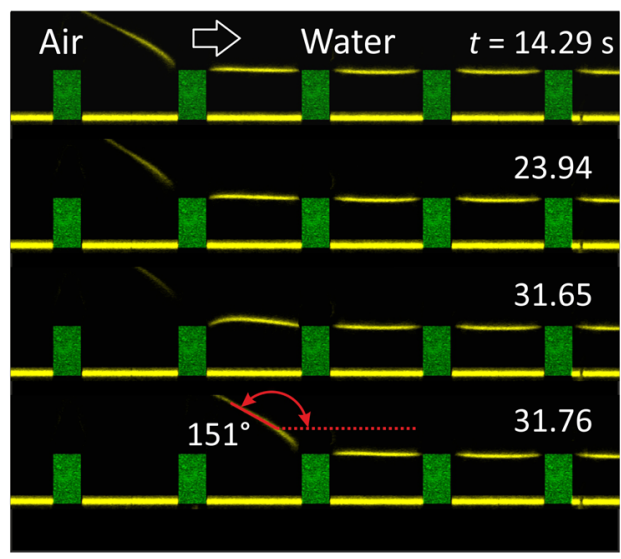

(b)

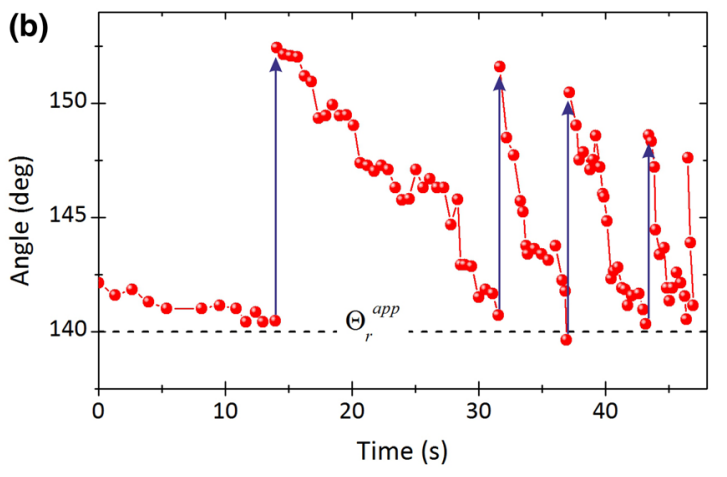

FIG. 4. Receding waterfront on a superhydrophobic micropillar array. (a) Confocal vertical cross section of the receding side of a water drop moving to the right on a superhydrophobic micropillar array $(a=10 \mu \mathrm{m}, b=30 \mu \mathrm{m}, h=16 \mu \mathrm{m})$. The inclination of $9^{\circ}$ was kept constant. The rear side detaches from the pillars at 14.3, $31.8,37.3,43.5$ s. After $46.6 \mathrm{~s}$, the drop gets out of the field of view and starts its fast slide downhill. The water-air and substrateair interfaces (yellow) are imaged in reflection. (b) Receding angles measured from confocal images plotted versus time. The dark blue arrows indicate jumps of the contact line.

macroscopic fit of the contour. The discontinuous movement and the fact that there is a lower critical angle is, in any case, consistent. The apparent receding contact angle observed with the goniometer $\left(\Theta_{r}^{\text {app }}=142 \pm 5^{\circ}\right)$ agrees with values recorded with the confocal microscope $\left(\Theta_{r}^{\mathrm{app}}=140 \pm 3^{\circ}\right)$.

Krasovitski and Marmur [106] pointed out that the front and rear contact angles of a drop just before sliding need not necessarily be identical to the apparent advancing and receding contact angles. Since we found that $\Theta_{a}^{\text {app }}=180^{\circ}$, which is an upper limit, and $\Theta_{r}^{\text {app }}$ observed with the goniometer and the confocal microscope agree with each other, we exclude such a difference in our case.

These observations have several implications. (i) A surface is commonly defined "superhydrophobic" when the apparent advancing contact angle of water exceeds $150^{\circ}$ and when the hysteresis $\Delta \Theta=\Theta_{a}^{\text {app }}-\Theta_{r}^{\text {app }}$ is lower than $10^{\circ}$. Both values are almost exclusively measured with a goniometer. Sometimes the second condition is replaced by demanding a low roll-off angle. Confocal microscope images demonstrate that the apparent advancing contact angle measured with a goniometer may be significantly underestimated. It depends on the way the drop is placed on the surface. We measured $165^{\circ}$ with the goniometer, but the real advancing contact angle on micropillars with flat top faces was $\Theta_{a}^{\text {app }}=180^{\circ}$. This implies that apparent advancing contact angles are not suitable to characterize superliquid-repellent surfaces. In fact, apparent advancing contact angles close to $180^{\circ}$ or even larger may even be characteristic for superhydrophobic surfaces. (ii) Underestimating $\Theta_{a}^{\mathrm{app}}$ in goniometer measurements also implies that $\Delta \Theta$ is underestimated. Therefore, superhydrophobicity should not be defined by a low contact angle hysteresis. (iii) In general, a drop rolls off an inclined surface when the tilt angle $\alpha$ exceeds a value given by $[15,21-23]$

$$
\sin \alpha=\frac{k \gamma w}{V \rho g}\left(\cos \Theta_{r}^{\mathrm{app}}-\cos \Theta_{a}^{\mathrm{app}}\right) .
$$

Here, $\gamma$ is the surface tension of the liquid, $w$ is the width of the apparent contact area measured perpendicular to the sliding direction, $V$ is the volume of the drop, $\rho$ is the density of the liquid, $g=9.81 \mathrm{~m} / \mathrm{s}^{2}$ is the acceleration of gravity, and $k \approx 1$ is a geometry factor. Equation (1) is the result of a force balance between gravitation pulling the drop downhill and the capillary force; i.e., the integral of surface tension around the contact line of the drop. Equation (1) is also valid for superhydrophobic surfaces as long as the drop is much larger than the spacing between protrusions. Our results show that for many if not all superhydrophobic surfaces, $\Theta_{a}^{\mathrm{app}} \approx 180^{\circ}$ and Eq. (1) should simplify

$$
\sin \alpha=\frac{k \gamma w}{V \rho g}\left(\cos \Theta_{r}^{\mathrm{app}}+1\right) .
$$

(iv) To design superhydrophobic surfaces and calculate apparent contact angles, usually the Cassie-Baxter theory is applied [7]. It is based on the minimization of the global Gibbs free energy. For a comparison with experiments, the equilibrium contact angle is often set equal to the apparent advancing contact angle [8], which leads to [7-9]

$$
\cos \Theta_{a}^{\mathrm{app}}=f(\cos \Theta+1)-1 .
$$

Here, $\Theta$ is the Young or materials contact angle as measured on a smooth, planar surface of the same material. It was later clarified that the surface fractions local to the drop perimeter need to be inserted [10-13]. Our observations demonstrate that the Cassie-Baxter equation does not reflect the underlying physical process. In our case $(f=4.9 \%$, $\Theta_{a}=124^{\circ}$ ), Eq. (3) predicts an equilibrium contact angle of $168^{\circ}$. Thus, the equilibrium contact angle is, indeed, in the range set by $\Theta_{r}^{\mathrm{app}}=140^{\circ}$ and $\Theta_{a}^{\mathrm{app}}=180^{\circ}$.

(v) We propose that for the definition of superhydrophobicity, the apparent receding contact angle is used. 
A surface should be called superhydrophobic if the apparent receding contact angle exceeds a certain value, e.g., $150^{\circ}$. A high apparent receding contact angle is inherently connected to a low roll-off angle. Furthermore, it has the advantage of being independent on drop size [97].

All superliquid-repellent surfaces, including surfaces which repel nonpolar liquids or solutions with surface active agents, rely on protrusions to establish the Cassie state. Therefore, micropillar arrays are a good model, and we expect the conclusions to be valid for all superliquidrepellent surfaces.

We thank Tadashi Kajiya, Nan Gao, Sanghyuk Wooh, and Periklis Papadopoulos for helpful discussions. Financial support from an ERC Grant No. 340391 SuPro (H. J. B.), COST1106 (D. V.), and the Marie Skłodowska-Curie fellowship 660523-NoBios-ESR (N. E.) are acknowledged.

*Corresponding author. butt@mpip-mainz.mpg.de

[1] W. Barthlott and C. Neinhuis, Planta 202, 1 (1997).

[2] J. P. Rothstein, Annu. Rev. Fluid Mech. 42, 89 (2010).

[3] Y. M. Zheng, H. Bai, Z. B. Huang, X. L. Tian, F. Q. Nie, Y. Zhao, J. Zhai, and L. Jiang, Nature (London) 463, 640 (2010).

[4] K. C. Park, S. S. Chhatre, S. Srinivasan, R. E. Cohen, and G. H. McKinley, Langmuir 29, 13269 (2013).

[5] N. Miljkovic and E. N. Wang, MRS Bull. 38, 397 (2013).

[6] M. Paven, P. Papadopoulos, S. Schöttler, X. Deng, V. Mailänder, D. Vollmer, and H.-J. Butt, Nat. Commun. 4, 2512 (2013).

[7] A. B. D. Cassie and S. Baxter, Trans. Faraday Soc. 40, 546 (1944).

[8] J. Bico, C. Marzolin, and D. Quéré, Europhys. Lett. 47, 220 (1999).

[9] A. Marmur, Langmuir 19, 8343 (2003).

[10] G. McHale, Langmuir 23, 8200 (2007).

[11] M. Nosonovsky, Langmuir 23, 9919 (2007).

[12] W. Choi, A. Tuteja, J. M. Mabry, R. E. Cohen, and G. H. McKinley, J. Colloid Interface Sci. 339, 208 (2009).

[13] H. Y. Erbil, Surf. Sci. Rep. 69, 325 (2014).

[14] D. Öner and T. J. McCarthy, Langmuir 16, 7777 (2000).

[15] Z. Yoshimitsu, A. Nakajima, T. Watanabe, and K. Hashimoto, Langmuir 18, 5818 (2002).

[16] C. Priest, T. W. J. Albrecht, R. Sedev, and J. Ralston, Langmuir 25, 5655 (2009).

[17] C. Dorrer and J. Rühe, Langmuir 23, 3179 (2007).

[18] C. Semprebon, S. Herminghaus, and M. Brinkmann, Soft Matter 8, 6301 (2012).

[19] See Supplemental Material at http://link.aps.org/ supplemental/10.1103/PhysRevLett.116.096101, for contact angles reported in the literature and description of the preparation of micropillar arrays, image processing, and how contact angles were determined.

[20] A. T. Paxson and K. K. Varanasi, Nat. Commun. 4, 1492 (2013).

[21] C. G. L. Furmidge, J. Colloid Sci. 17, 309 (1962).
[22] A. ElSherbini and A. Jacobi, J. Colloid Interface Sci. 299, 841 (2006).

[23] C. Antonini, F. J. Carmona, E. Pierce, M. Marengo, and A. Amirfazli, Langmuir 25, 6143 (2009).

[24] Y. I. Frenkel, J. Exp. Theor. Phys. 18, 659 (1948).

[25] M. Miwa, A. Nakajima, A. Fujishima, K. Hashimoto, and T. Watanabe, Langmuir 16, 5754 (2000).

[26] C. Semprebon and M. Brinkmann, Soft Matter 10, 3325 (2014).

[27] G. E. Fogg, Nature (London) 154, 515 (1944).

[28] F. E. Bartell and J. W. Shepard, J. Phys. Chem. 57, 211 (1953).

[29] R. H. Dettre and R. E. Johnson, SCI Monogr. 25, 144 (1967).

[30] H. J. Busscher, I. Stokroos, H. C. Vandermei, P. G. Rouxhet, and J. M. Schakenraad, J. Adhes. Sci. Technol. 6, 347 (1992).

[31] S. Shibuichi, T. Onda, N. Satoh, and K. Tsujii, J. Phys. Chem. 100, 19512 (1996).

[32] W. Chen, A. Y. Fadeev, M. C. Hsieh, D. Öner, J. Youngblood, and T. J. McCarthy, Langmuir 15, 3395 (1999).

[33] A. Nakajima, A. Fujishima, K. Hashimoto, and T. Watanabe, Adv. Mater. 11, 1365 (1999).

[34] J. P. Youngblood and T. J. McCarthy, Macromolecules 32, 6800 (1999).

[35] K. Tadanaga, J. Morinaga, A. Matsuda, and T. Minami, Chem. Mater. 12, 590 (2000).

[36] D. O. H. Teare, C. G. Spanos, P. Ridley, E. J. Kinmond, V. Roucoules, J. P. S. Badyal, S. A. Brewer, S. Coulson, and C. Willis, Chem. Mater. 14, 4566 (2002).

[37] H. Y. Erbil, A. L. Demirel, Y. Avci, and O. Mert, Science 299, 1377 (2003).

[38] A. Lafuma and D. Quéré, Nat. Mater. 2, 457 (2003).

[39] L. Feng, Z. Y. Zhang, Z. H. Mai, Y. M. Ma, B. Q. Liu, L. Jiang, and D. B. Zhu, Angew. Chem., Int. Ed. Engl. 43, 2012 (2004).

[40] N. J. Shirtcliffe, S. Aqil, C. Evans, G. McHale, M. I. Newton, C. C. Perry, and P. Roach, J. Micromech. Microeng. 14, 1384 (2004).

[41] W. Ming, D. Wu, R. van Benthem, and G. de With, Nano Lett. 5, 2298 (2005).

[42] M. Hikita, K. Tanaka, T. Nakamura, T. Kajiyama, and A. Takahara, Langmuir 21, 7299 (2005).

[43] X. Wu and G. Shi, J. Phys. Chem. B 110, 11247 (2006).

[44] Y. Tian, H. Q. Liu, and Z. F. Deng, Chem. Mater. 18, 5820 (2006).

[45] D. Bartolo, F. Bouamrirene, E. Verneuil, A. Buguin, P. Silberzan, and S. Moulinet, Europhys. Lett. 74, 299 (2006).

[46] G. R. J. Artus, S. Jung, J. Zimmermann, H. P. Gautschi, K. Marquardt, and S. Seeger, Adv. Mater. 18, 2758 (2006).

[47] L. C. Gao and T. J. McCarthy, J. Am. Chem. Soc. 128, 9052 (2006).

[48] L. Zhai, M. C. Berg, F. C. Cebeci, Y. Kim, J. M. Milwid, M. F. Rubner, and R. E. Cohen, Nano Lett. 6, 1213 (2006).

[49] T. Baldacchini, J.E. Carey, M. Zhou, and E. Mazur, Langmuir 22, 4917 (2006).

[50] J. Y. Shiu and P. Chen, Adv. Funct. Mater. 17, 2680 (2007).

[51] I. A. Larmour, S. E. J. Bell, and G. C. Saunders, Angew. Chem., Int. Ed. Engl. 46, 1710 (2007). 
[52] L. Barbieri, E. Wagner, and P. Hoffmann, Langmuir 23, 1723 (2007).

[53] Y. M. Zheng, X. F. Gao, and L. Jiang, Soft Matter 3, 178 (2007).

[54] H. J. Tsai and Y. L. Lee, Langmuir 23, 12687 (2007).

[55] J. M. Mabry, A. Vij, S. T. Iacono, and B. D. Viers, Angew. Chem., Int. Ed. Engl. 47, 4137 (2008).

[56] M. Reyssat, J. M. Yeomans, and D. Quéré, Europhys. Lett. 81, 26006 (2008).

[57] R. Rioboo, M. Voue, A. Vaillant, D. Seveno, J. Conti, A. I. Bondar, D. A. Ivanov, and J. De Coninck, Langmuir 24, 9508 (2008).

[58] C. Pirat, M. Sbragaglia, A. M. Peters, B. M. Borkent, R. G. H. Lammertink, M. Wessling, and D. Lohse, Europhys. Lett. 81, 66002 (2008).

[59] S. Sarkar, A. Chunder, W. F. Fei, L. N. An, and L. Zhai, J. Am. Ceram. Soc. 91, 2751 (2008).

[60] J. Zhang, X. Sheng, and L. Jiang, Langmuir 25, 1371 (2009).

[61] B. Bhushan, Y. C. Jung, and K. Koch, Langmuir 25, 3240 (2009).

[62] M. S. Bobji, S. V. Kumar, A. Asthana, and R. N. Govardhan, Langmuir 25, 12120 (2009).

[63] Y. C. Jung and B. Bhushan, Langmuir 25, 14165 (2009).

[64] K. Koch, B. Bhushan, Y. C. Jung, and W. Barthlott, Soft Matter 5, 1386 (2009).

[65] Y. Kwon, N. Patankar, J. Choi, and J. Lee, Langmuir 25, 6129 (2009)

[66] A. M. Peters, C. Pirat, M. Sbragaglia, B. M. Borkent, M. Wessling, D. Lohse, and R. G. H. Lammertink, Eur. Phys. J. E 29, 391 (2009).

[67] B. Deng, R. Cai, Y. Yu, H. Jiang, C. Wang, J. Li, L. Li, M. Yu, J. Li, L. Xie, Q. Huang, and C. Fan, Adv. Mater. 22, 5473 (2010).

[68] R. Poetes, K. Holtzmann, K. Franze, and U. Steiner, Phys. Rev. Lett. 105, 166104 (2010).

[69] J. Y. Shiu, C. W. Kuo, W. T. Whang, and P. L. Chen, Lab Chip 10, 556 (2010).

[70] Y. Li, L. Li, and J. Sun, Angew. Chem., Int. Ed. Engl. 49, 6129 (2010).

[71] Q. F. Xu, B. Mondal, and A. M. Lyons, ACS Appl. Mater. Interfaces 3, 3508 (2011).

[72] B. D. Brandner, P. M. Hansson, A. Swerin, P. M. Claesson, M. Wahlander, J. Schoelkopf, and P. A. C. Gane, Soft Matter 7, 1045 (2011).

[73] T. Kobayashi, K. Shimizu, Y. Kaizuma, and S. Konishi, Appl. Phys. Lett. 98, 123706 (2011).

[74] M. Krasowska, M. Ferrari, L. Liggieri, and K. Malysa, Phys. Chem. Chem. Phys. 13, 9452 (2011).

[75] C. Lee and C.-J. Kim, Phys. Rev. Lett. 106, 014502 (2011).

[76] G. Liu, L. Fu, A. V. Rode, and V. S. J. Craig, Langmuir 27, 2595 (2011)

[77] X. Deng, L. Mammen, Y. F. Zhao, P. Lellig, K. Müllen, C. Li, H.-J. Butt, and D. Vollmer, Adv. Mater. 23, 2962 (2011).

[78] H. Mertaniemi, V. Jokinen, L. Sainiemi, S. Franssila, A. Marmur, O. Ikkala, and R. H. A. Ras, Adv. Mater. 23, 2911 (2011).
[79] J. P. Zhang and S. Seeger, Angew. Chem., Int. Ed. Engl. 50, 6652 (2011).

[80] B. J. Privett, J. Youn, S. A. Hong, J. Lee, J. Han, J. H. Shin, and M. H. Schoenfisch, Langmuir 27, 9597 (2011).

[81] B. Samuel, H. Zhao, and K. Y. Law, J. Phys. Chem. C 115, 14852 (2011)

[82] Z. Cheng, H. Lai, M. Du, S. Zhu, N. Zhang, and K. Sun, Soft Matter 8, 9635 (2012).

[83] H. J. Ensikat, M. Mayser, and W. Barthlott, Langmuir 28, 14338 (2012).

[84] J. Groten, C. Bunte, and J. Rühe, Langmuir 28, 15038 (2012).

[85] H. Zhou, H. X. Wang, H. T. Niu, A. Gestos, X. G. Wang, and T. Lin, Adv. Mater. 24, 2409 (2012).

[86] J. V. I. Timonen, M. Latikka, R. H. A. Ras, and O. Ikkala, Nat. Commun. 4, 2398 (2013).

[87] N. Miljkovic, D. J. Preston, R. Enright, and E. N. Wang, Nat. Commun. 4, 2517 (2013).

[88] P. Olin, S. B. Lindstrom, T. Pettersson, and L. Wagberg, Langmuir 29, 9079 (2013).

[89] H. Teisala, M. Tuominen, M. Aromaa, M. Stepien, J. M. Makela, J. J. Saarinen, M. Toivakka, and J. Kuusipalo, Colloid Polym. Sci. 291, 447 (2013).

[90] J.E. Rodriguez, A. M. Anderson, and M. K. Carroll, J. Sol-Gel Sci. Technol. 71, 490 (2014).

[91] L. B. Boinovich and A. M. Emelyanenko, Colloids Surf. A 481, 167 (2015).

[92] Y. Cao, L. Yuan, B. Hu, and J. Zhou, Nanotechnology 26, 315705 (2015).

[93] M. Jung, T. Kim, H. Kim, R. Shin, J. Lee, J. Lee, J. Lee, and S. Kang, Appl. Surf. Sci. 351, 920 (2015).

[94] H. Wang, E. Chen, X. Jia, L. Liang, and Q. Wang, Appl. Surf. Sci. 349, 724 (2015).

[95] S. Srinivasan, G. H. McKinley, and R. E. Cohen, Langmuir 27, 13582 (2011).

[96] L. Gao and T. J. McCarthy, Langmuir 22, 2966 (2006).

[97] J. T. Korhonen, T. Huhtamaki, O. Ikkala, and R. H. A. Ras, Langmuir 29, 3858 (2013).

[98] E. Pierce, F. J. Carmona, and A. Amirfazli, Colloids Surf. A 323, 73 (2008).

[99] F. E. Bartell and J. W. Shepard, J. Phys. Chem. 57, 455 (1953).

[100] C. W. Extrand, Langmuir 18, 7991 (2002).

[101] Y. T. Cheng, D. E. Rodak, A. Angelopoulos, and T. Gacek, Appl. Phys. Lett. 87, 194112 (2005).

[102] M. Nosonovsky and B. Bhushan, Langmuir 24, 1525 (2008).

[103] P. Papadopoulos, L. Mammen, X. Deng, D. Vollmer, and H. J. Butt, Proc. Natl. Acad. Sci. U.S.A. 110, 3254 (2013).

[104] E. L. Decker, B. Frank, Y. Suo, and S. Garoff, Colloids Surf. A 156, 177 (1999).

[105] K. G. Winkels, I. R. Peters, F. Evangelista, M. Riepen, A. Daerr, L. Limat, and J. H. Snoeijer, Eur. Phys. J. Spec. Top. 192, 195 (2011).

[106] B. Krasovitski and A. Marmur, Langmuir 21, 3881 (2005). 